\title{
EBOLA VIRUS DISEASE: AWARENESS AMONG DENTAL STUDENTS IN HUNGARY
}

\author{
KATALin KÁROLYHÁZY ${ }^{1}$, BALÁZS FAZEKAS ${ }^{2}$, JANKA FAZEKAS ${ }^{3}$, \\ PÉTER HERMANN ${ }^{1}$ and KRISZTINA MÁRTON ${ }^{4 *}$ \\ ${ }^{1}$ Department of Prosthodontics, Dental Faculty, Semmelweis University, \\ Budapest, Hungary \\ ${ }^{2}$ Whipps Cross University Hospital, London, UK \\ ${ }^{3}$ Northwick Park Hospital, Harrow, Middlesex, UK \\ ${ }^{4}$ Department of General Dental Preclinical Practice, Dental Faculty, \\ Semmelweis University, Budapest, Hungary
}

(Received: 27 April 2016; accepted: 24 June 2016)

Introduction: The Ebola epidemic has claimed thousands of lives in Africa, and there has been a mounting pressure on the healthcare systems around the globe to prepare for the showing up of patients infected with this virus. Junior clinicians are at the forefront of medical teams, often coming into contact with patients first, during clerking and admissions. This study assesses the level of knowledge of Ebola virus disease (EVD) among dental students at Semmelweis University, Budapest, Hungary. Materials and methods: A cross-sectional survey of 257 dental students was carried out across five different courses. Each of the students was asked to fill out a detailed questionnaire comprising of 11 questions, to assess their knowledge about signs and symptoms, investigations, management, and sequelae of the virus and the outbreak. Findings: This study highlighted that there is an overall lack of knowledge about critical aspects of EVD among dental students. We found that the participating students scored less than $60 \%$ for 8 of the 11 questions, including those assessing their recognition and subsequent management of EVD. Conclusion: These results are concerning and the medical universities and dental schools need to act fast to prepare the Hungary's dental (and medical) students and junior doctors for an inevitable influx of infected patients.

Keywords: Ebola virus, awareness, dental students, prophylaxis, questionnaire

\section{Introduction}

Although, according to the recent World Health Organization (WHO) Situation report, the current Ebola epidemic has been finished [1], it claimed

*Corresponding author; E-mail: marton.krisztina@dent.semmelweis-univ.hu 
thousands of lives in Africa and there has been a mounting pressure on the healthcare systems around the globe to prepare for the arrival of patients infected with this virus. This current Ebola epidemic in West Africa has claimed 11,316 lives [1], leading the WHO to declare it an "Emergency of International Concern" [2]. The outbreak originated in the Guéckédou district of Guinea in December 2013 and has reached several countries, namely Sierra Leone, Liberia, Mali, and Senegal [3]. The number of infected persons has been 28,639 (up to 16 March 2016) since the beginning of the outbreak - December 2013 according to the recent data of WHO [1]. Governments of these countries have spent millions in an attempt to contain the humanitarian crisis, while health systems across the whole world are currently preparing to deal with a potential epidemic at their own pace $[4,5]$.

The Zaire Ebola virus (EBOV), a member of the Ebolavirus genus, is responsible for the current outbreak in West Africa [6]. Ebolaviruses are enveloped negative-strand RNA viruses with approximately 19 kilobases; to date five subtypes have been identified, with four of these causing severe hemorrhagic disease in humans and primates [7]. Alongside with the Marburg genus, they belong to Filoviridae family of viruses, which characteristically form infectious filamentous particles.

Patients who are infected by the virus undergo different stages of symptomology [8]. Initially, after an incubation period of 2-21 days, patients typically develop non-specific symptoms of fever, myalgia, and chills. Subsequently, gastrointestinal symptoms of diarrhea and vomiting become more pronounced, and there may be a rapid deterioration with multi-organ failure and hemorrhage. The current case fatality rate is exceptionally high, estimated to be at $70.8 \%$, validating the Centers for Disease Control and Prevention's (CDC's) concern of its use as a bioterrorism agent [9]. Health care workers have also been frequently infected in medical facilities. No specific treatment or vaccine is yet available for Ebola hemorrhagic fever but new promising drug therapies are being evaluated $[10,11]$.

The WHO and the CDC both agree that early recognition of the symptoms and a rapid response to these could potentially reduce the impact of an Ebola outbreak $[10,11]$. Many authors highlight that medical systems need to be more prepared for a potential outbreak $[12,13]$. In UK, the government has provided guidelines for medical practitioners to recognize and manage patients suffering from Ebola virus disease (EVD) [14]. However, despite all the corroborating evidence regarding the importance of staff education in dealing with outbreaks, there have been only a limited number of studies, which have assessed the knowledge and awareness of EVD within medical staff. Lakhani et al. [15] have investigated the baseline level of knowledge regarding viral hemorrhagic fever 
(VHF) among healthcare personnel in two large hospitals in Pakistan in 2002. They reported a poor level of understanding of the disease among healthcare professionals, with only $57 \%$ of doctors being aware of the common signs and symptoms of VHF. They also highlighted the potential dangers of insufficient knowledge among healthcare workers and recommended a fast-track education campaign to correct this. In addition, Bluemke et al. [16] recently evaluated the level of readiness of the radiological community for a potential outbreak of EVD; they also underlined a lack of understanding among medical staff and recommended that they should receive further training regarding EVD. It was also revealed that junior doctors in England do not have up-to-date knowledge of the clinical symptoms and characteristics of the EVD [17].

Students at the Dental Faculty of the Semmelweis University treat regularly patients from the second semester of the third year of their study. Although EVD is not in the syllabus of the subjects and is not queried on the exams, students obtain information about the Ebola virus at the fifth semester of their curriculum, in the frame of the general and oral microbiology subject, while infection control policies are taught in the second year in the General Dental Preclinical Practice course. A wide variety of nations are represented both in the English and in the German speaking programs among the students: Iranian, Canadian, Norwegian, British, Israeli, Cyprian, Greek, Syrian, Saudi-Arabian, Irish, Holland, Korean, Vietnamese, Pakistani, Turkish, German, Austrian, Ugandan, Romanian, Russian, Libyan, Polish, Chinese, Mauritian, Australian, and Nigerian. This study seeks to evaluate the awareness of EVD among the fourth-year and fifth-year dental students in Hungary. These groups of students are regularly treating patients in teaching hospitals and are often involved at the frontline of dental care in the university dental hospitals in Hungary. Currently, Hungary and Eastern Europe face a high number of migrants, permitting a high burden onto the national health care system. The consequences of poor understanding are clear: the lives of patients, the doctors themselves and the general public are at risk and the spread of the epidemic may also be facilitated. The aim of this study is to elucidate whether these consequences are probable and if so, in what ways could these risks be mitigated.

\section{Materials and Methods}

To ascertain the level of knowledge about Ebola among dental students, we devised a questionnaire based on our literature search, the one that was employed in a previous study [17]; then we distributed printed copies of this questionnaire among the dental students of the fourth-year and the fifth-year 
course at the Semmelweis University, Dental Faculty, Budapest, Hungary: Fifth-year Hungarian students $(n=78)$, fifth-year English language course students $(n=27)$, fifth-year German language course students $(n=13)$, and fourthyear Hungarian students $(n=85)$, the fourth-year English language course students $(n=26)$, and the fourth-year German language course students $(n=28)$ formed a fourth year foreign language group $(n=54)$. Electronic copies were also circulated to increase the participation in the target group. In each case, permission to distribute the questionnaires was sought from and granted by the dean of the dental faculty. Data collection was carried out between 2nd of March and 8th of May 2015.

A total of 257 dental students completed the questionnaire; 118 were filled out by fifth-year dental students and the remaining 139 were answered by the fourth-year dental students. All of the attempted questionnaires were included in our analysis, none were disregarded.

The questionnaire focused on assessing the dental students' knowledge about the demographics and presentation of EVD, as well as the investigations, management and sequelae of an infection. A comprehensive mark scheme was devised using multiple information sources, including the WHO, CDC, Health Protection Agency (HPA), and the local protocols. The answers were subsequently collected, and each of the questions was scored according to the mark scheme by one person (KK) and checked by another (KM); then the results were analyzed.

\section{Analysis}

The first step was to calculate the frequency of every possible mark for each question in the questionnaire (i.e., the number of dental students receiving 0 mark, 1 mark, or 2 marks, etc.) (Table I). The sum of the available marks multiplied by the frequency of each mark provided the total marks reached by the participants for that question [17]. Subsequently, the percentage of total marks achieved by the dental students was calculated, indicating the approximate level of their understanding (Table II). To reduce bias, we included here the mark scheme that we used to allocate marks and we also calculated the frequency for the most common answers for each of the questions, and for those answers that we considered to demonstrate underlying knowledge by the participant, e.g., administration of intravenous fluids, or 21 days for incubation period (Table I). The data were subsequently stratified according to the different student groups to allow us to draw comparisons between them (Table II). Then the average score of the different student groups was statistically analyzed by the paired Student's $t$-test at a significance level of $p<0.05$. 
Table I. Scheme used to allocate marks among dental students regarding their Ebola virus disease awareness [17]

Incubation period (2 marks)

- 2 marks for 2-21 days

- 1 mark for any other answers within the range inc 21 days

- 0 mark for obvious incorrect answers

Route of transmission (2 marks)

- 2 marks for body fluids/secretions (including stool, urine, saliva or semen, mucosal secretions, feco-oral, fecal, blood, sweat)

- 1 mark for fomites, e.g., bed linen, used needles. Cumulative.

- 0 mark for incorrect answers, e.g., air, respiratory, contact fluid/contact with fluid, fluid, airborne, close contacts - too vague, body contact, direct contact, sweat, droplet spread, oral-cutaneous, skin to skin, direct transmission, fluids, person to person

Countries affected by the current Ebola outbreak (4 marks)

- 4 marks - 1 for each country:

Guinea, Sierra Leone, Liberia, Mali, Senegal, USA/Spain, Nigeria

- 0 mark if clearly incorrect or for more vague answers like West Africa

Immediate management of an Ebola patient (3 marks)

1 mark for each of

- ID seniors/Micro/HPA

- Quarantine - isolate the patient into a single side room. Barrier nursing.

- Universal precautions - wear appropriate personal protective equipments, (infection control measures), restrict contact, avoid aerosol-generating procedures. Transfer to RYF.

Count but do not allocate marks to i.v. fluids, blood tests (Investigations including full blood count,

U\&Es, LFTs, clotting screen, CRP, glucose and blood cultures, malaria screening)

No marks for contact tracing/DoH/CDC/check protocol/transfer to unit

Mark given for inform authorities, no direct contact - do not take Ix until, no exam/obs, no

bloods/cannula, suits (referring to PPP)

Signs and symptoms (5 marks)

- 1 mark if mentions any of the following:

$\circ$ Fever

- Severe headache

- Muscle pain

- Weakness

$\circ$ Fatigue

- Diarrhea

- Vomiting

- Abdominal (stomach) pain

- Unexplained hemorrhage (bleeding or bruising)

- Sore throat

- Rash

Possible ways of diagnosing EVD question (2 marks)

- 2 marks for any of the following:

- Viral RNA detection

- Viral antigen detection

- ELISA, PCR, EM, Immunohistochemistry

- Viral antibodies

- 1 mark for non-specific/vague, e.g., serology, blood test (FBC, LFTs, U\&Es, clotting) microscopy

- 0 mark for clearly incorrect answers, e.g., virology, blood film, blood cultures, sputum cultures, viral screen, viral test 
Table I. (cont.)

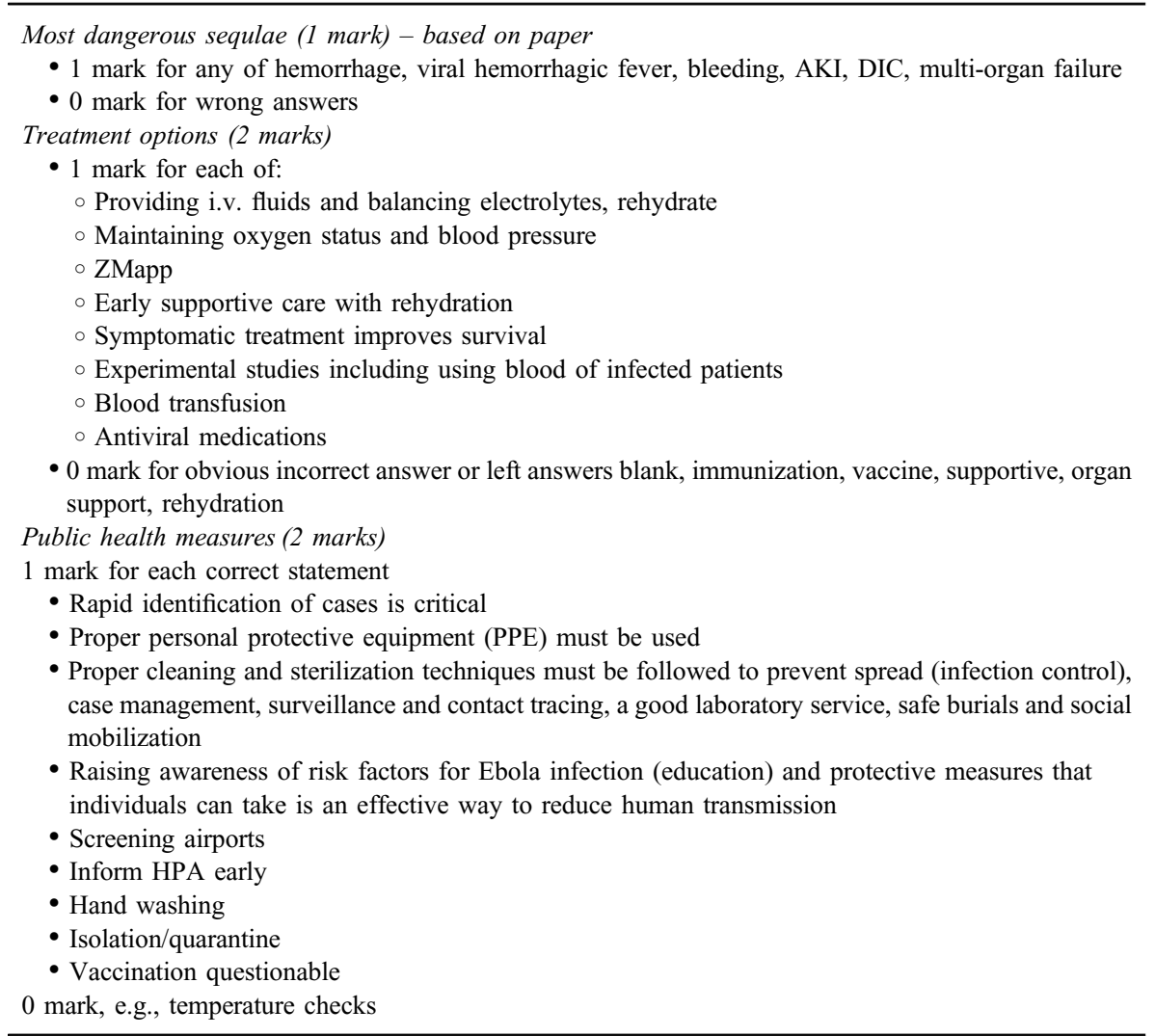

\section{Results}

The results are summarized in Table II. Twenty-six out of 257 students (10.5\%) correctly stated the incubation period of EVD to be 2-21 days - the range quoted by the WHO, CDC, and HPA. A further 217 students were aware of the important 21-day cut-off period, which is perhaps more important information in respect to the spread of the disease. With these responses counted, the percentage of students responding correctly was $84.4 \%$.

Considering the route of transmission of the virus, $29.2 \%$ of respondents correctly identified body fluid (e.g., blood, semen, saliva, vomitus, and feces) as a potential route of spread, with a further 5.9\% naming fomites as transmission agents. The most frequent incorrect answer provided was the "respiratory route," with about $52.5 \%$ of participants giving this answer. 


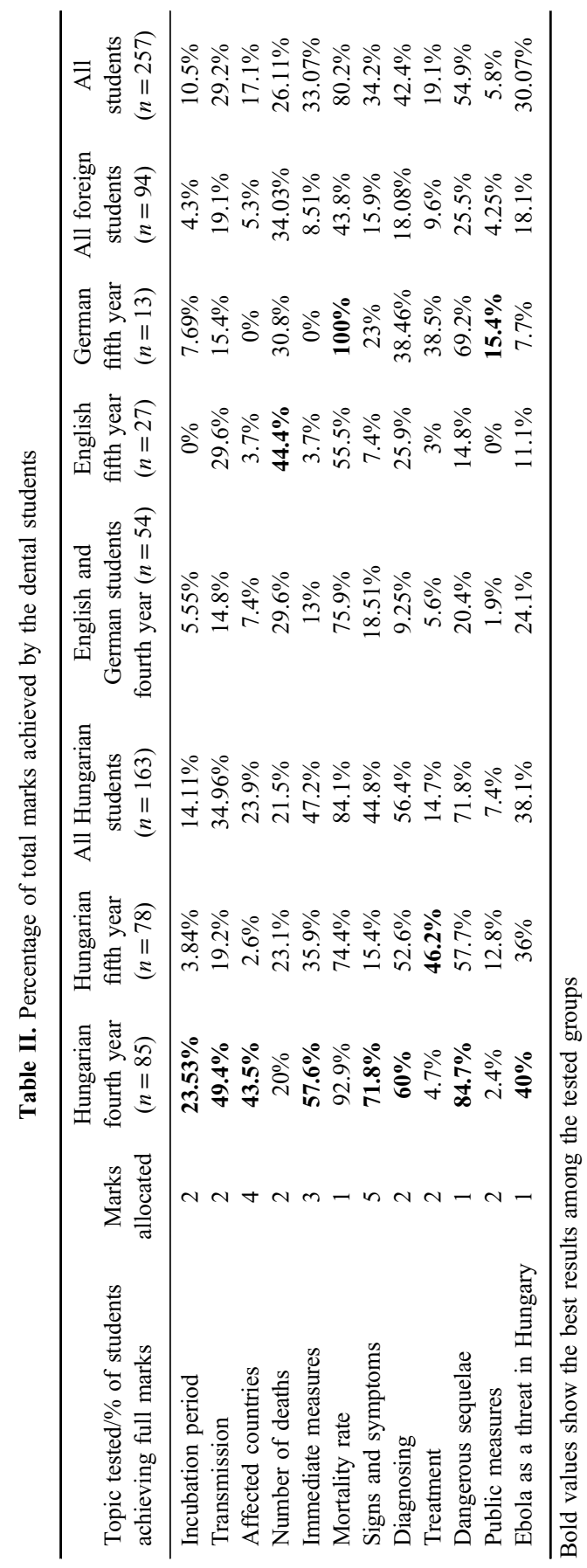


The geographical distribution of the Ebola epidemic formed the basis of the third question. About $17.1 \%$ of the respondents were able to name four or more countries affected by the current epidemic, with an additional $19.0 \%$ of students being aware of three affected countries, and $9.7 \%$ of doctors appeared to have no knowledge of the geographical distribution of the outbreak, with $4.2 \%$ not answering the question at all. Within the period of study, the official death toll from EVD was 8,800 [18] cases based on WHO data, with 35\% of the students giving the $>5,000$ answer, while $13.2 \%$ of the estimated the death toll from EVD to $<2,000$, whereas $26.1 \%$ of the participants were convinced that the death toll had a range between 2,000 and 5,000.

The study found that only $33.1 \%$ of students were able to list three of the preliminary management steps when faced with a suspected EVD patient - as accepted by most of the hospital protocols. Specifically, $70.0 \%$ of dental students recognized the importance of isolation of the infected patient, $66.1 \%$ of students are aware of the involvement of their local infectious disease and microbiology teams, and $41.2 \%$ of students recognized the value of taking universal precautions when caring for such patients. When asked about the mortality rate of EVD, $65.8 \%$ of participating doctors recognized that EVD had a mortality rate greater than $50 \%$, whereas $10.5 \%$ considered this to be less than $30 \%$.

The frequencies of the reported responses for the common symptoms of Ebola are highlighted in Figure 1. About 34.2\% of participants were able to name five or more of the common symptoms with $22.6 \%, 20.2 \%$, and $12.8 \%$ being able to name four, three, and two symptoms, respectively. About $6.0 \%$ of students were not able to identify any symptoms of EVD. According to our questionnaire,

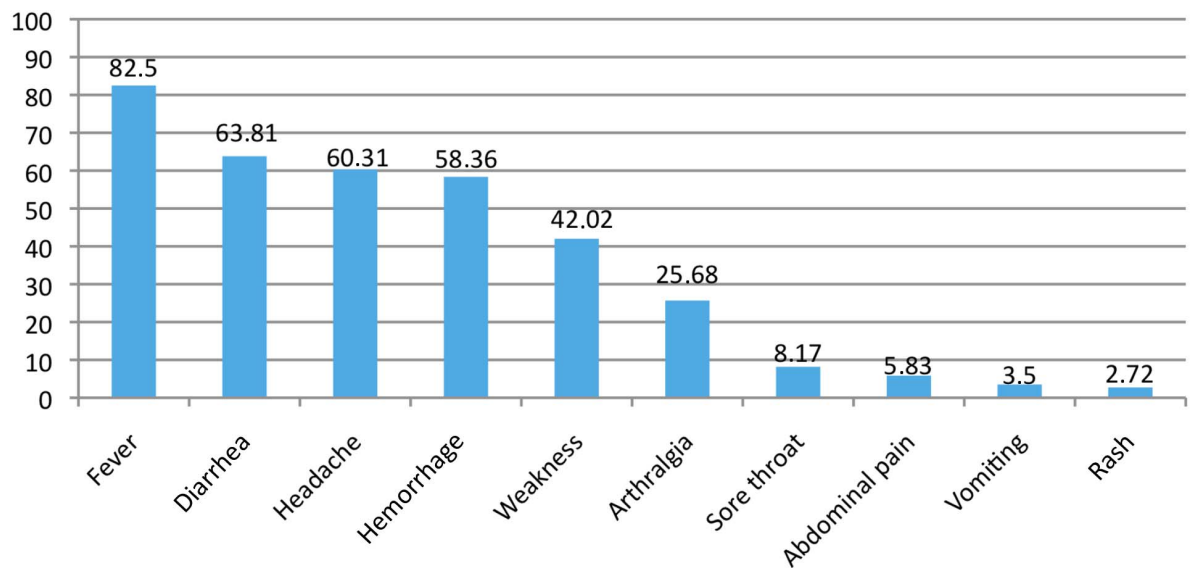

Figure 1. Percentage of dental students recalling the common symptoms of EVD 
$24.12 \%$ of students were able to name specific diagnostic techniques used to confirm EVD, with a further $42.4 \%$ able to give more general investigative measures of EVD, such as blood cultures or serology. With regard to acceptable treatment options for patients infected with the EBOV, 50.2\% considered starting fluid replacement as a form of treatment in ill patients. Furthermore, $19.0 \%$ of the responders were aware of a new drug currently under development, ZMapp, which comprises three chimeric monoclonal antibodies. About $55.0 \%$ of the students correctly identified the most common dangerous sequelae associated with EVD, namely that of hemorrhage, shock, and subsequent multi-organ failure (Table II).

The penultimate question focused on public health measures that should be undertaken to contain an epidemic. About $74.7 \%$ of students suggested acceptable public health interventions such as personal protective equipment, screening airports, and rapid identification that could be implemented to minimize further transmission of the virus. About $59.5 \%$ mentioned isolation of infected patients as a public measure, whereas $13 \%$ of doctors thought that increasing public awareness through education or training was crucial. The final question attempted to gauge whether dental students perceived the current EBOV epidemic to be a threat in Hungary. About $31 \%$ of the respondents believed Hungary to be at a substantial risk of an Ebola outbreak, while 51\% did not feel threatened by the epidemic.

\section{Inter-class Comparisons (Table II)}

Students of the fourth-year Hungarian course achieved the highest overall score of 17.9 for all the questions combined, followed by the fifth-year German course with an overall score of 14.8 , which was significantly less compared with the fourth-year Hungarian group ( $p<0.0001$ by the Student's $t$-test), the fifth-year Hungarian course with 13.7 scores, statistically was not different from the fifthyear Germans while the fourth-year English and German course with 11 scores provided a significantly weaker result compared with the previous ones. Fifth-year English course participants achieved the lowest overall score, gaining 10.2 of the attainable marks. This attribute was not different statistically from the forgoing group. The overall difference was also significant between the student groups (analyzed by the one-way ANOVA test, $p<0.0001$, Figure 2). Other differences were also evident across the five groups. Fifth-year English group achieved the lowest combined score of $3.7 \%$ for the management section of EVD. At this group, 1 of the 27 students listed intravenous fluid resuscitation as part of their management of an EVD patient, while 4 did not give any answer. Universitybased protocols stress that there should be absolutely no medical staff contact with 


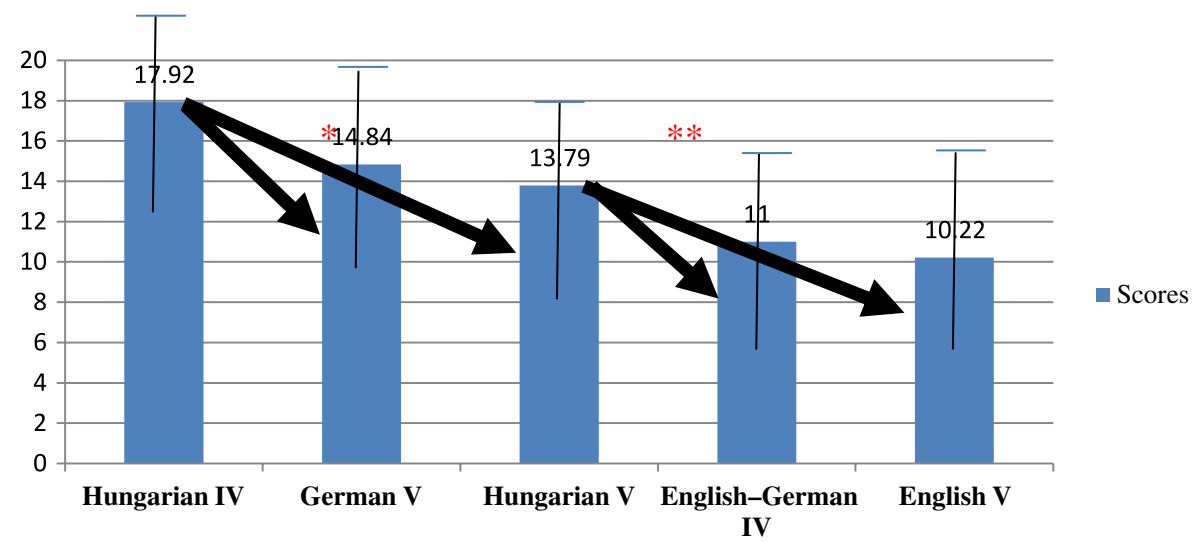

Figure 2. Average EVD awareness scores of the different dental courses. ${ }^{*}: p<0.0001$ by the Student's $t$-test; Hungarian fourth-year course provided the best result, followed by the German and the Hungarian fifth-year course with a significantly reduced knowledge; **: $p<0.0001$ by the Student's $t$-test; German and English fourth-year and English fifth-year courses provided the weakest result, which was significantly reduced compared with the second level courses

potentially infected patients in teaching departments until the patient has been cleared by the Infectious Diseases Team. The other four student groups in the study were more familiar with this cardinal rule, but one dental student of the German fifth-year group also said that he would attempt intravenous fluid resuscitation in a suspected Ebola patient.

\section{Discussion}

The relatively small sample size of our study and in terms of the number of dental students limits the statistical validity of the conclusions of the results. Moreover, despite our best efforts to use strict criteria from validated sources and to keep track of the answers provided, the format of asking short answer questions introduced a classification bias as some more ambiguous answers were marked correct according to our mark scheme, while others were marked incorrect.

Despite these limitations, this study has highlighted that there is a lack of understanding about some critical aspects of EVD among dental students. Overall, the participating students scored an average of $60 \%$ for the questions, including those about the signs and symptoms, and areas affected by the epidemic and diagnostic measures. These results resemble those presented by Lakhani et al. [15] who similarly found that only $57 \%$ of doctors in Pakistan knew the common signs and symptoms of VHF in 2002. 
This apparent lack of understanding could not only be detrimental to immediate patient care but may also potentially influence the dynamics of transmission as it may delay the recognition of EVD by the students and also by the clinicians, who may be the first to come into contact with newly admitted patients. Lloyd et al. [19] described the importance of the recognition of EVD by clinicians and the benefits of training of physicians to increase their awareness. The fact that only $34.5 \%$ of students could list three correct preliminary management steps is also noteworthy and may require additional attention.

Public Health Department (PHD) of the Semmelweis University has emphasized the importance of educating staff about Ebola ever since the beginning of the outbreak. The discrepancy between their efforts and the apparent lack of understanding may be explained by the fact that PHD focused primarily on teachers and leaders of the university departments, not on the students [20]. Second, it may be that information is not disseminating from experts to students effectively; however, each of the participating students in this study was sent e-mails about Ebola on the intranet pages. These may need to be updated and made more accessible.

This study has many implications for the education departments. It has highlighted a deficit in the level of knowledge among dental students, a problem that needs to be tackled to prepare better medical systems for EVD. This study could be used as a platform to initiate a more extensive survey to assess awareness of EVD not only among students but also among clinicians of all grades, as well as Nurses and Allied Health Care Professionals. If these findings are confirmed by other similar studies, e-learning modules, active real-time courses, or simulation scenarios should be prepared and delivered to the relevant groups to improve recognition and management of EVD. Hopefully, with these measures a better awareness of clinicians will be achieved [21].

In conclusion, this study highlights that dental students do not seem to have sufficient knowledge about EVD and its subsequent management. In the light of our results, we would recommend a compulsory e-learning module to be adopted for dental and medical students and for junior doctors to improve their understanding of this disease. Furthermore, practical workshops and interactive teaching sessions by experts would also be of benefit within all healthcare institutes in Hungary.

\section{Acknowledgement}

Each author states that none of them is in a financially related state regarding this manuscript. 


\section{Conflict of Interest}

The authors declare no conflict of interest.

\section{References}

1. World Health Organization: Ebola situation report - 16 March 2016. 2016. Available from: http://apps.who.int/ebola/current-situation/ebola-situation-report-16-March-2016, accessed 24 March 2016.

2. WHO: Ebola virus disease. 2015. Available from: http://www.who.int/features/ebola/en/, accessed 22 January 2016.

3. Briand, S., Bertherat, E., Cox, P., Formenty, P., Kieny, M. P., Myhre, J. K., Roth, C., Shindo, N., Dye, C.: The international Ebola emergency. N Engl J Med 371, 1180-1183 (2014).

4. BBC: UK government to match $£ 5 \mathrm{~m}$ of public's Ebola donations. 2015. Available from: http://www.bbc.com/news/uk-29822276, accessed 15 March 2015.

5. KFF: Health systems in the U.S., Africa, Asia prepare to diagnose, care for Ebola patients. 2014. Available from: http://kff.org/news-summary/health-systems-in-u-s-africa-asiaprepare-to-diagnose-care-for-ebola-patients, accessed 15 March 2015.

6. Carroll, S. A., Towner, J. S., Sealy, T. K., McMullan, L. K., Khristova, M. L., Burt, F. J., Swanepoel, R., Rollin, P. E., Nichol, S. T.: Molecular evolution of viruses of the family Filoviridae based on 97 whole-genome sequences. J Virol 87, 2608-2616 (2013).

7. Ansari, A. A.: Clinical features and pathobiology of Ebola virus infection. J Autoimmun 55, 1-9 (2014).

8. Goeijenbier, M., van Kampen, J. J., Reusken, C. B., Koopmans, M. P., van Gorp, E. C.: Ebola virus disease: A review on epidemiology, symptoms, treatment and pathogenesis. Neth J Med 72, 442-448 (2014).

9. CDC: Bioterrorism agents/diseases. Emergency preparedness and response. 2014. Available from: http://emergency.cdc.gov/agent/agentlist.asp, accessed 15 March 2015.

10. CDC: Case definition for Ebola virus disease. 2014. Available from: http://www.cdc. gov/vhf/ebola/healthcare-us/evaluating-patients/case-definition.html, accessed 15 March 2015.

11. WHO: WHO statement on the meeting of the International Health Regulations Emergency Committee regarding the 2014 Ebola outbreak in West Africa. 2014. Available from: http:// www.who.int/mediacentre/news/statements/2014/ebola-20140808/en/, accessed 15 March 2015.

12. Ki, M.: What do we really fear? The epidemiological characteristics of Ebola and our preparedness. Epidemiol Health 36, 1-4 (2014).

13. Benowitz, I., Ackelsberg, J., Balter, S. E., Baumgartner, J. C., Dentinger, C., Fine, A. D., Harper, S. A., Jones, L. E., Laraque, F., Lee, E. H., Merizalde, G., Quinn, C., Slavinski, S., Winters, A. I., Weiss, D., Yacisin, K. A., Varma, J. K., Layton, M. C.: Surveillance and preparedness for Ebola virus disease - New York City, 2014. MMWR Morb Mortal Wkly Rep 63, 934-936 (2014).

14. Public-Health-England: Ebola virus disease: Clinical management and guidance. 2014. Available from: https://www.gov.uk/government/collections/ebola-virus-disease-clinicalmanagement-andguidance, accessed 15 March 2015. 
15. Lakhani, A., Mahmood, H., Laeeq, A., Mansoor, S., Lodhi, S., Majid, S., Kizilbash, Q., Altaf, A.: Viral hemorrhagic fever in Pakistan: Awareness among health care personnel. J Pak Med Assoc 52, 214-217 (2002).

16. Bluemke, D. A., Meltzer, C. C.: Ebola virus disease: Radiology preparedness. Radiology 274, 527-531 (2015).

17. Fazekas, B., Fazekas, J., Moledina, M., Fazekas, B., Karolyhazy, K.: Ebola virus disease: Awareness among junior doctors in England. J Hosp Infect 90, 260-262 (2015).

18. World Health Organization: Ebola situation report. 2015. Available from: http://apps.who. int/ebola/current-situation/ebola-situation-report-28-january-2015, accessed 29 May 2015.

19. Lloyd, E. S., Zaki, S. R., Rollin, P. E., Tshioko, K., Bwaka, M. A., Ksiazek, T. G., Calain, P., Shieh, W. J., Kondé, M. K., Verchueren, E., Perry, H. N., Manguindula, L., Kabwau, J., Ndambi, R., Peters, C. J.: Long-term disease surveillance in Bandundu region, Democratic Republic of the Congo: A model for early detection and prevention of Ebola hemorrhagic fever. J Infect Dis 179, S274-S280 (1999).

20. PHE: Ebola: Public health questions and answers. Public Health England - Ebola virus disease: Clinical management and guidance. 2014. Available from: https://www.gov.uk/ government/collections/ebola-virus-disease-clinical-management-and-guidance, accessed 15 March 2015.

21. Tosh, P. K., Sampathkumar, P.: What clinicians should know about the 2014 Ebola outbreak. Mayo Clin Proc 89, 1710-1717 (2014). 